\title{
Comunicación

\section{La prensa como objeto de estudio. Panorama actual de las formas de hacer historia de la prensa en México}

\author{
Celia del Palacio MonTIEL*
}

El presente trabajo da a conocer algunos de los esfuerzos hechos en México para profundizar en la historia de la prensa mexicana de los siglos XIX y XX y de qué manera esos esfuerzos (formación de grupos de trabajo, organización de eventos académicos, elaboración de páginas electrónicas especializadas y publicaciones) han contribuido a la formación de un nuevo «campo» de estudio. Se revisarán particularmente, las publicaciones en torno a la historia de la prensa, entre los años 1998 y 2004, tomando en cuenta el campo disciplinar de donde vienen los autores, así como lugar de publicación.

También se mencionarán las tesis de posgrado.

PALABRAS CLAVE: historia de la prensa, periodismo mexicano.
This article presents some of the efforts made in México in the last few years in order to make deeper studies of the history of Mexican press of the XIXth and XXth centuries.

The author also writes about how these efforts (the formation of work groups, organization of academic events, specialized electronic pages elaboration, and different kinds of publications) have contributed to the formation of a new disciplinary «field». The books about press history that appeared between the years of 1998-2004, will be especially revised, taking into account the authors, disciplinary field and place of publication. The Master's and PH.D. dissertations will be also mentioned.

KEY WORDS: press history, mexican journalism.

* Universidad de Guadalajara.

Correo electrónico: celiadelp@yahoo.com.mx 
El objetivo del presente trabajo es dar a conocer algunos de los esfuerzos que se han hecho en los últimos años para profundizar en la historia de la prensa en México.

La historia de la prensa en México apenas puede comenzar a pensarse como campo de estudio en formación, entendiendo campo, como «espacio sociocultural de posiciones objetivas donde los agentes luchan por la apropiación de capital común» (Fuentes, 1998: 11). En este sentido, resulta importante consignar aquí varios esfuerzos, tanto desde el Distrito Federal, como de las regiones que han redundado en la formación de ese campo a través de un mayor interés por el rescate de periódicos y su análisis, no sólo como fuentes para la historia, sino también como objeto de estudio por sí mismos. Estos esfuerzos se han visto reflejados en la formación de grupos especializados, la organización de eventos académicos sobre el tema y el establecimiento de páginas electrónicas para especialistas. Mientras que en una segunda instancia, también han redundado en la publicación de libros. Inicialmente, se hará un recorrido por las nuevas iniciativas propiciadas por instituciones del Distrito Federal, así como de las regiones, para promover estos estudios y, posteriormente, se hará una revisión de los libros publicados entre 1998 y 2004.

\section{NUEVAS INICIATIVAS PARA EL ESTUDIO}

\section{DE LA HISTORIA DE LA PRENSA}

La creación de la Red de Historiadores de la Prensa en Iberoamérica marca un hito en ese sentido. En las tres reuniones que se han dado en su seno: 1998 en Guadalajara, 2002 en Morelia y 2004 en Jalapa, se ha dado énfasis deliberado a los estudios sobre prensa como objeto de estudio.

Por otro lado, los dos congresos organizados por la Universidad Autónoma Metropolitana (UAM) con el nombre de «El papel de la prensa en las ciencias sociales», han propiciado también acercamientos al objeto periodístico más allá de la descripción erudita.

Este ha sido el caso también del I Encuentro Nacional de Investigación Bibliohemerográfica, auspiciado por el Instituto de Investigaciones Bibliográficas de la Universidad Nacional Autónoma de México (UNAM), en 2003, donde se reunieron los investigadores interesados en el tema. 
Es importante subrayar la labor del Seminario de Bibliografía Mexicana, impartido en esa misma dependencia, el cual ha realizado el rescate y la ordenación de los materiales hemerográficos de la Hemeroteca Nacional, haciéndolos asequibles al público a través de sus recién aparecidos índices. Dentro del seminario también han tenido lugar diplomados y otros cursos sobre la historia de la prensa y el periodismo mexicano.

Otro grupo cuya importancia no debe soslayarse, es el que se reunió en diversos seminarios en torno al proyecto Editores de la Ciudad de México, del Instituto de Investigaciones José María Luis Mora y el Instituto de Investigaciones Bibliográficas de la UNAM, donde, a pesar del nombre que llevó, acogió a los investigadores interesados en el estudio no sólo de editores, sino de periódicos de las regiones.

Por otro lado, también es importante señalar la existencia de la Fundación Buendía, que a través de su Seminario de Historia de los Medios, ha dado espacio a estudios sobre prensa, tanto en el centro, como en diversas regiones del país.

También se ha creado un grupo de investigación fuera de la ciudad de México, el cual reúne estudiosos de las regiones para constituir un primer acercamiento a la historia de la prensa más allá de la ciudad de México: se trata del Proyecto Historia Comparativa de la Prensa Regional en México, 1795-1950, apoyado por CONACYT.

Es innegable la importancia que han adquirido las nuevas tecnologías de la comunicación para la difusión de las ideas y su capacidad para llegar a un número cada vez mayor de receptores. Con el fin de aprovechar esas ventajas, los historiadores de la prensa han creado recientemente páginas electrónicas dedicadas a su tema de estudio. Llama la atención que haya sido fuera de la ciudad de México donde se han proyectado. Una de ellas nació en Baja California Sur ${ }^{1}$ y la otra, es el órgano de difusión de la Red ya citada, con sede en la Universidad de Guadalajara (UdeG). ${ }^{2}$

Todos los datos anteriores tienen relevancia, ya que explicarán la relativa proliferación de nuevos acercamientos a la historia de los periódicos mexicanos, posteriores a 1998, de los que se hablará más adelante.

1 http://historiaperiodismo.tripod.mx

2 www.historiadoresdelaprensa.com.mx 


\section{NUEVOS LIBROS SOBRE HISTORIA}

DE LA PRENSA (1998-2004)

\section{Suscribimos absolutamente la opinión de que}

Recuperar, sistematizar y poner a disposición de los investigadores en ejercicio y en formación los documentos que permitan construir los estados de la cuestión pertinentes a sus proyectos, al mismo tiempo que disponer de una base de información que facilite la evaluación continua de la producción del campo, puede contribuir a incrementar la reflexividad necesaria para orientar, desde los agentes y las instituciones académicas, las acciones estratégicas para consolidar y legitimar el propio campo (Fuentes, 2003: 9).

Hace algunos años en un artículo que pretendía hacer una historiografía mínima de la historia de la prensa en México, se hablaba de diversas tareas pendientes para aquellos historiadores interesados en el tema, entre ellas, «un acercamiento medianamente profundo a [la prensa regional] en un país compuesto por regiones muy diversas, cada una con una prensa muy diferente en características físicas como en contenidos» (Del Palacio, 1998:9-46); también se mencionaba ahí que la historia de la prensa mexicana se ha hecho desde el Centro y que lo que más se conoce de ella es aquella prensa generada en la ciudad de México. Se dijo igualmente que eran muy pocos los investigadores, además de los eruditos bibliógrafos locales, quienes habían emprendido historias del periodismo de los estados, aunque se puntualizaba que las excepciones eran los historiadores de la nueva generación y los estudiosos de la comunicación.

Las cosas han cambiado desde hace seis años, pero no lo suficiente para que aquellas aseveraciones dejen de tener sentido. La historia de la prensa sigue siendo un tema de investigación que se ha privilegiado en la zona centro y que muchos libros que pretenden abarcar la historia de la prensa en México como país, en realidad hablan de la historia de la prensa en la ciudad de México. Esto responde en buena parte al desconocimiento y desinterés por los procesos regionales, por una parte; y por otra, la falta de interés de los historiadores locales por incursionar en los estudios sobre prensa. 
Es entendible que la mayor parte de las investigaciones sobre historia de la prensa se realicen en la capital, básicamente por que ahí se encuentran los archivos y hemerotecas más completos y mejor conservados (no hablaremos aquí de otros posibles factores, como los apoyos diferenciados a la investigación y la calidad también distinta de las escuelas de comunicación y de historia). ${ }^{3}$

En las regiones, además de la falta de apoyos para la investigación, encontramos la ausencia de los materiales hemerográficos, base fundamental de una investigación de este tipo. La situación de los archivos estatales y municipales en la mayor parte de los estados es lamentable, debido principalmente a que pocos lugares cuentan con los recursos económicos y humanos para la preservación adecuada de los materiales.

Sin embargo, hay cosas que afortunadamente han cambiado desde la publicación de aquel artículo, en lo que se refiere a la investigación sobre historia de la prensa. Una de ellas es el mayor número de interesados en las distintas regiones del país en incursionar en ese campo.

En este trabajo, se hará un recorrido por 44 libros publicados en la República Mexicana entre 1998 y 2004, sobre la historia del periodismo nacional. ${ }^{4}$ No se incluirán aquí los artículos ni las tesis, ya que aquellas

3 Hacer un análisis más profundo sobre estos aspectos, sería materia de otro artículo. Resultaría conveniente tomar en cuenta que el acervo de la Hemeroteca Nacional sigue siendo la referencia obligada para cualquier estudio histórico sobre prensa. Afortunadamente en dicho repositorio se conservó una buena parte de las publicaciones periódicas de los estados, en parte debido a que era obligatorio enviar un ejemplar a dicho archivo, además de los contenidos hemerográficos de los acervos que se han ido adquiriendo a través del tiempo. Gracias a los materiales contenidos en la Hemeroteca Nacional ha sido posible reconstruir la historia hemerográfica de muchas regiones, las cuales por diversas causas, entre ellas el descuido, los factores climatológicos, las guerras y las invasiones, por nombrar algunas, habían perdido parte importante de su memoria periodística. Existen además en el Distrito Federal otros repositorios de vital importancia, como el Archivo del Centro de Estudios Históricos de CONDUMEX y el Archivo General de la Nación, sin olvidar la Biblioteca del Museo Nacional de Antropología e Historia, que contiene algunos materiales hemerográficos.

4 La lista completa se anexa en un cuadro al final del trabajo. No se ha incluido en la bibliografía, para no confundir estos libros con las otras obras de consulta. 
a las que tuvimos acceso, no constituyen un número suficientemente representativo. 5 Se prefirió condensar el corpus a fin de ahondar un poco en los contenidos y categorías de análisis.

El artículo citado de 1998, hace una clasificación de los estudios históricos sobre prensa en las siguientes categorías: 1) estudios generales, 2) estudios eruditos, 3) estudios regionales, 4) estudios monográficos, 5) estudios sobre un momento histórico particular, 6) estudios sobre impresores y periodistas, 7) estudios sobre un tipo específico de prensa, 8 ) relaciones entre periodismo y literatura, 9) estudios sobre legislación y prensa, 10) estudios sobre papel, litografía y artes gráficas, 11) estudios sobre géneros periodísticos, 12) hemerografías y otras guías y 13) opiniones en torno a la prensa.

En el presente trabajo, se ha partido del mismo material analizado, para elaborar una clasificación distinta. Por ejemplo, ya no aparecieron «opiniones en torno a la prensa» ni «estudios sobre géneros periodísticos», tampoco trabajos que se abocaran a estudiar las «relaciones entre periodismo y literatura». Esto nos permite pensar que las preocupaciones en torno a la investigación histórica de la prensa se han modificado $\mathrm{y}$, de alguna manera, profesionalizado.

Se ha optado, tomando como base estas tendencias, por las siguientes categorías:

\section{Obras colectivas}

Se observó que abundan las obras colectivas, muchas de ellas resultado de congresos, coloquios y reuniones académicas sobre el tema.

5 El libro de Raúl Fuentes Navarro (2003) es una fuente autorizada para ser tomada como base, ya que se trata de un recuento exhaustivo de trabajos sobre comunicación aparecidos entre 1995-2000; sin embargo, en lo que a tesis de posgrado se refiere, sólo se consignan 10 trabajos de egresados de universidades mexicanas (casi todas son de la maestría en Ciencias de la Comunicación, de la Facultad de Ciencias Políticas y Sociales de la UNAM), mientras que como artículos, considera los capítulos de los libros que aquí se toman en cuenta y dos artículos más de revistas nacionales. La cantidad no nos parece suficiente como para hacer inferencias significativas. De cualquier modo, se incluyen dos cuadros, de ninguna manera exhaustivos, con las tesis y los artículos que llegaron a nuestro conocimiento, al final del trabajo. 
La explicación de este fenómeno se encuentra en el crecimiento de mecanismos de evaluación académica, donde publicar libros o artículos en revistas indexadas y libros con ISBN, se vuelve una estrategia de supervivencia. Lo que antes se publicaba como Memorias o Actas de tal o cual reunión, ahora lleva un título y se presenta como libro. Esto no necesariamente debe verse como algo negativo, ya que este tipo de publicaciones tienen mucha mayor circulación que las antiguas Memorias, que sólo llegaban a los mismos participantes. Estos libros colectivos (en la presente recopilación encontramos ocho, 18.18\%) deben estudiarse en un apartado particular, ya que cada uno de ellos contiene estudios de todo tipo que guardan relación con la prensa.

En estos libros encontramos 169 capítulos, de los cuales sólo 37 se ocupan de la provincia mexicana (21.89\%). Sin embargo, de esos 169 capítulos, la gran mayoría se interesan en la prensa como objeto de estudio, lo cual es un avance respecto a la situación que guardaba este tipo de estudios antes de 1998, cuando se abordaba a la prensa como fuente para el estudio de un problema o periodo histórico en particular.

En el libro Empresa y cultura en tinta y papel, 1800-1860 (Suárez de la Torre, 2001), 6 trabajo final del proyecto cuyo tema de estudio era fundamentalmente los editores de la ciudad de México, debido a su bien acotada temática, sus 45 capítulos tienen que ver con impresores, editores e imprentas. Está dividido en los siguientes apartados: «Problemática e intereses editoriales»; «Las imprentas en la ciudad de México»; «Impresores de provincia» (aquí se incluyen análisis sobre Puebla, Michoacán, Guadalajara y Veracruz); «Libreros, librerías y gabinetes de lectura»; «De lecturas»; «Proyectos culturales»; «Tendencias y problemáticas culturales»; «Éxitos editoriales», y «Periodismo y literatura». Aunque una buena parte de los capítulos que se ocupan de analizar la actividad de los impresores, abordan también por fuerza el caso del periodismo. El libro contiene 11 capítulos dedicados exclusivamente a él.

6 Las referencias completas de cada una de estas obras las encontrará el lector en el cuadro anexo, al final de este trabajo. No se han incluido estos libros en la bibliografía. El lector puede localizarlos en el cuadro por su título, autor o año de publicación. 
En el llamado Del autor al lector (Castañeda, 2002), en realidad el tema de la prensa se trata de una manera periférica, en uno solo de sus capítulos, ya que el mayor interés es la cultura del libro, no sólo en México, sino en otros lugares de América.

Por otro lado, Tipos y caracteres. La prensa mexicana, 1822-1855 (Castro, 2001) aborda distintos aspectos de la historia de la prensa en México (centro y regiones), privilegiando a los periódicos como objeto de estudio, así como estudiando a sus editores, sus impresores y sus escritores, durante estos años tan decisivos en la historia de México. Está formado por 24 capítulos divididos en los siguientes apartados: «Edificar la nación», «Forjadores de tipos y caracteres», «Intereses, compromisos y aficiones» y «Voces de la plazas»; en este último, se abordan diversos aspectos de la historia de la prensa en las regiones de Michoacán, Veracruz, Chiapas, Puebla y Yucatán.

En La prensa decimonónica en México (Pineda y Del Palacio, 2003), los 20 capítulos se refieren, como el mismo título indica, al siglo XIX, abordando distintos aspectos de la prensa: libertad de imprenta, relaciones entre literatura y prensa, el periódico como empresa, relación del periódico con sus públicos, análisis comparativos entre regiones, análisis cuantitativos de prensa, análisis del discurso periodístico, entre otros. Seis de los capítulos abordan la problemática de la prensa en las regiones de Oaxaca, Michoacán, Tlaxcala, Sinaloa, Guadalajara, Veracruz y Guanajuato.

Aunque La prensa en México (Navarrete y Aguilar, 1998), por su mismo nombre pareciera abarcar más allá de la prensa capitalina, no incluye ni un solo estudio sobre la provincia; se enfoca en los diversos aspectos relacionados con la historia de los periódicos mexicanos: periodistas, tipos de prensa: prensa femenina y masculina o humorística, y la imagen de don Porfirio en la prensa, entre otros.

Bicentenario de la prensa provincial en México (Morosini, 2004), es la reunión de algunos de los trabajos más recientes sobre la prensa en Veracruz, con motivo del bicentenario de la publicación del Jornal económico mercantil, primer periódico publicado fuera de la ciudad de México, precisamente en Veracruz, en 1804. Sus cinco capítulos abordan visiones generales sobre el periodismo y estudios monográficos, además de partes de un censo de publicaciones veracruzanas hasta 2004. 
Historia de la prensa en Iberoamérica (Del Palacio, 2000), tiene varias preocupaciones: las relaciones entre prensa y región; estudios de caso; el periódico como empresa; legislación, publicidad y prensa; la historia en la prensa; la prensa como producto cultural y formador de opinión pública; reflexiones sobre el trabajo periodístico, y planteamientos metodológicos para estudiar la historia de la prensa. De sus 36 capítulos, sólo siete se abocan al estudio de los periódicos en las regiones. Se abordan los casos de Durango, Oaxaca, Michoacán, Veracruz y Guadalajara.

La historia de la prensa en Oaxaca (Grañén et al., 1999) como su nombre lo indica, está consagrada a esta temática. Sus cuatro capítulos abordan distintos aspectos de la imprenta en aquel estado: sus orígenes, su desarrollo entre 1821 y 1876, imprentas durante el Porfiriato y la revolución y algunas impresiones del siglo XX.

\section{La prensa y el periodismo como fuente para otros estudios históricos}

Como se dijo anteriormente, este tipo de acercamiento a la prensa ya no abunda en la misma proporción que en años anteriores. En este caso sólo encontramos tres libros $(6.81 \%)$, donde se toma a la prensa como fuente, para el estudio de algún otro tema relacionado con la historia política o cultural.7 Ninguno de ellos se refiere a lugares fuera de la ciudad de México.

\section{Recopilaciones y selección de artículos, fotografías y caricaturas}

Aparecieron en estos últimos años seis obras (13.63\%) que toman directamente materiales de los periódicos, ya se trate de artículos, editoriales o imágenes -caricaturas, grabados o fotografías- sobre un tema en particular. Aquí también incluimos una edición facsimilar. ${ }^{8}$ Tres de ellos se ocupan de periódicos de la provincia (Sinaloa, Guadalajara y Oaxaca).

7 El Nacional y el hijo del Ahuizote, dos visiones de la Independencia de Cuba, 1895-1898 (Espinoza, 1998); México 1900. Percepciones y valores en la gran prensa diaria (Pérez Rayón, 2001); La caricatura política en el México del siglo XIX (Acevedo, 2000).

8 Yerba, goma y polvo. Drogas, ambientes y policías en México, 1900-1940 (Pérez Montfort, 1999); La obra periodística de Amado Nervo en El Correo de la Tarde, 1892-1894 (Fonseca, 2002); Imágenes de México. Las historias de El Buen Tono de Juan B. Urrutia, 1909-1912 (Camacho, 2002); Vida cotidiana en la ciudad de México 1850-1910 (Barros y Buenrrostro, 2003); Los 
4. Índices, catálogos y otras guías

A diferencia de 1998, en esta nueva recopilación abundan los índices, catálogos y otras guías, de los cuales se encontraron 11 (25\%), no sólo de hemerotecas y archivos de la ciudad de México, sino también (seis) de otros lugares del país: el Sureste, Oaxaca, Chiapas, Michoacán, Zacatecas y Veracruz. ${ }^{9}$

\section{Historias generales del periodismo}

Sólo figuran en esta selección dos obras $(4.5 \%)$ de carácter más general: una El periodismo en México, 500 años de historia (Ruiz Castañeda y Reed, 1998), referente a toda la historia de la prensa en México; y otra, Los orígenes del periodismo en nuestra América (Benítez, 2003), sobre la prensa en «nuestra América», epíteto más bien lírico del autor para referirse a América Latina.

En este apartado también se incluyen dos historias de la prensa (4.5\%): El siglo de cumplido. Emergencia del periodismo mexicano de opinión (Lombardo, 2002) e Imágenes del deseo, arte y publicidad en la prensa ilustrada mexicana, 1894-1939 (Ortiz, 2003), las cuales pretenden ser abarcadoras de todo el país y en realidad sólo abordan, única o mayormente, a la prensa en la ciudad de México en uno de sus aspectos como es la emergencia del periodismo de opinión, o el arte y la publicidad en la prensa.

oaxaqueños pintados por sí mismos. La caricatura en el periódico El Ciclón, 1927-1929 (Sánchez Silva y Ruiz Cervantes, 2004), y La palabra, edición facsimilar (Nuño Rodríguez, 2002).

9 El estadio. La prensa en México, 1870-1879 (Abramo y Barberena, 1998); Índice del Fondo Hemerográfico veracruzano (Del Palacio, 1999); Índice de revistas literarias del siglo XIX (ciudad de México) (Ruiz Castañeda, 1999); Publicaciones periódicas mexicanas del siglo XIX, 1822-1855 (Castro, 2000); Bibliohemerografía del sureste mexicano y Centroamérica. Época colonial (Gordillo, 2001); Estudio e índice onomástico del Diario de México (Martínez, 2002); Publicaciones periódicas mexicanas del siglo XIX, 1856-1876 parte I (Castro, 2003); Catálogo Hemerográfico de Michoacán (Pineda, 2004); Catálogo de la Hemerografía de Zacatecas (Flores, 2005); Catálogo Hemerográfico de Chiapas (Martínez, 2004), y Catálogo hemerográfico de Oaxaca (Sánchez Silva y Ruiz Cervantes, 2005). 


\section{Historias regionales}

También hay seis obras particulares $(13.63 \%)$ que se refieren a la historia del periodismo en una región durante un periodo de tiempo determinado: Guadalajara durante la guerra de Independencia; los inicios de la prensa en Guadalajara; la prensa en Sinaloa durante el Porfiriato; el periodismo en Chiapas; la prensa política michoacana en el siglo XIX y la historia de la hemeroteca Néstor Sánchez de Oaxaca. ${ }^{10}$

\section{Estudios monográficos}

Al igual que en los años anteriores a 1998, continúan produciéndose los estudios monográficos, ya sea de un periódico o de un periodista particular. De los seis localizados $(13.63 \%)^{11}$, cuatro $(66.6 \%)$ pertenecen a las regiones de Chiapas, Oaxaca y dos a Nuevo León.

\section{¿Y LAS REGIONES?}

Aunque ya se han mencionado algunos datos, es necesario reiterar que de todos los libros incluidos en este estudio, encontramos una cantidad significativa que se refiere a las regiones de fuera del Distrito Federal.

De los 169 artículos contenidos en ocho obras colectivas, 37 (21.89\%) abordan estudios sobre las regiones. De estas ocho obras una está totalmente dedicada a Veracruz (12.5\%) y una a Oaxaca (12.5\%); tres de los seis libros de selección de materiales (50\%); seis de los 11 índices (50\%), y cuatro de los seis estudios monográficos (66.6\%) se

10 Imprenta, impresores y periódicos en Guadalajara 1793-1811 (Castañeda, 1999); La disputa por las conciencias, los inicios de la prensa en Guadalajara 1809-1835 (Del Palacio, 2001); Treinta años, historia y testimonios. Hemeroteca Pública de Oaxaca. Néstor Sánchez, 1992-2002 (Sánchez, 2002); La prensa en Sinaloa durante el cañedismo, 1877-1911 (Briones Franco, 1999); La prensa maniatada. El periodismo en Chiapas de 1827 a 1958 (Martínez, 2004), y Registro de la prensa política michoacana, siglo XIX (Pineda, 2004).

11 Mariano de Jesús Torres. Un polígrafo moreliano (Pineda, 1999); El Despertador Americano (Fregoso, 2001); El periódico oficial de Nuevo León. Un periódico con 175 años de vida (Torres López, 2001); El periódico El Imparcial. Primer diario moderno de México, 1896-1914 (García, 2003); Tiempo de Saber. Prensa y poder en México (Scherer y Monsivais, 2003) ; Ricardo Arenales. El poeta colombiano que fundó El Porvenir (Torres López, 2004). 
refieren a periódicos, periodistas o procesos de fuera de la ciudad de México.

De esta manera, puede apreciarse que el panorama de los estudios de la prensa regional no es tan pesimista como pudiera pensarse.

\section{Lugar de publicación}

Por otro lado, si atendemos al lugar de publicación de las obras, ya no prevalece el centralismo que ya se había mencionado. De los 44 libros, 22 fueron publicados en el Distrito Federal (50\%). No es poca la descentralización y el creciente interés en la provincia de publicar a sus autores (50\% comparado con 33.3\% de la recopilación hecha en 1998).

\section{Origen disciplinar}

En cuanto al origen disciplinar de los autores de estas obras, podría pensarse que resulta un tanto irrelevante, ya que hemos ido construyendo durante estos seis años, vínculos entre las disciplinas; sin embargo, procuraremos hacer algunas precisiones en este sentido.

Por un lado, se vuelve muy complicado etiquetar a los intelectuales dedicados al estudio de estos temas: ¿cómo llamar a alguien que estudió Letras y luego una maestría en Comunicación y un doctorado en Historia, para citar un caso extremo?, ¿dónde clasificar a Carlos Monsiváis?

Por otro lado, existe ahora mayor apertura en los encuentros académicos que se abocan al estudio de problemas o temas, más que en disciplinas y son bienvenidos a participar todos aquellos que puedan aportar luces en torno a un tema, vengan de donde vengan.

En cuanto a historia de la prensa en México, de los 42 autores o coordinadores registrados, siguen siendo mayoría los historiadores $(26=61.9 \%)$ y literatos $(6=14.2 \%)$, lo cual puede obedecer al creciente auge de la Nueva Historia (ya no tan nueva, por lo demás) o historia cultural, la cual reivindica el estudio de objetos hasta hace poco olvidados por la historia tradicional.

Uno de los temas privilegiados de esa nueva forma de hacer historia, es la historia de los impresos, que autores como Roger Chartier y Robert Darnton, además de Armando Petrucci, entre otros, hicieron popular en las últimas décadas. Las obras de estos autores no se popularizaron en México, sino hasta después de 1980. 
Los periodistas o aficionados, por otro lado, ya no publican tanto como antes ( $6=14.28 \%$ del total). Esto nos habla de una creciente profesionalización de este tipo de estudios.

Llama la atención observar, por otra parte, que los comunicólogos han perdido el interés por estos temas, ya que sólo encontramos a tres de estos especialistas $(7.14 \%)$ como autores o coordinadores de estos libros; al parecer temas como las nuevas tecnologías y la globalización, entre otros, son los temas de moda, en cuanto a estudios de la comunicación se refiere. Muchos de ellos, en los inicios de la profesionalización del campo, emprendieron la tarea de escribir las historias de los medios, que por lo demás, no existían; sin embargo, en los últimos años, este esfuerzo se hace innecesario y han volcado su atención hacia otros temas. 12

\section{Fundamentación teórica y metodológica}

Si se intenta efectuar un análisis somero de cuáles son los fundamentos teóricos y metodológicos de estos trabajos, se descubrirá que la mayoría de ellos sigue orientándose a la descripción de los fenómenos periodísticos. Muchos son estudios historiográficos que siguen la metodología tradicional de recolección e interpretación de las fuentes. Son muy pocos los trabajos que intentan vincular a los periódicos con su momento y explicar sus devenires en relación con los acontecimientos no sólo políticos, sino sociales y económicos. Ver a los periódicos dentro de su ecosistema comunicativo es algo que casi ninguno de los autores ha logrado.

Si se hiciera un recuento de citas, actividad que excede los límites de este trabajo, se encontraría una mayoría de Chartier y Darnton, seguidos muy de lejos por Habermas y Bourdieu. Los libros de Chartier se popularizaron en México en la década de 1990, encontrando seguidores ávidos en los historiadores que realizan estudios sobre impresos.

12 Es preciso hacer una puntualización a lo anterior, si se toman en cuenta las 10 tesis de posgrado que registra Fuentes (2001), las cuales provienen de maestrías en comunicación, mientras que sólo dos, de las cuatro a las cuales se tuvo acceso por otras vías, provienen de escuelas de Historia. La temporalidad que abordan estos trabajos es en su mayoría de finales del siglo XX. 
Los acercamientos teóricos y metodológicos que han sido utilizados desde hace años por los comunicólogos, por ejemplo, la Teoría de las Mediaciones de Manuel Martín Serrano, que podrían aplicarse en su riqueza y complejidad mucho mejor a los estudios sobre prensa, prácticamente no se ha utilizado (una sola tesis hace referencia a ella).

Otras teorías de la comunicación pueden ser perfectamente empleadas para hacer historia del periodismo, por ejemplo, el enfoque histórico-estructural, tal como ha sido planteado por Enrique Sánchez Ruiz (1992).

Sánchez Ruiz contempla las mediaciones de la producción social de comunicación masiva, incluyendo mediaciones históricas y estructurales (políticas, sociales y culturales), además de las mediaciones institucionales y organizacionales y finalmente las discursivas (1992: 80). Todas ellas pueden analizarse con gran provecho en las empresas periodísticas del pasado y sus productos.

Por otro lado, el importantísimo papel que jugaron los periódicos para la constitución de la esfera pública literaria y política en México a lo largo del siglo XIX, es muy pocas veces abordado en los estudios antes citados. Se encuentran casi nulas referencias directas a Habermas, 13 mientras que encontramos mayor acercamiento a François Xavier Guerra y Annick Lempérière (Pineda, 2004).

\section{BALANCE TENTATIVO}

A pesar de que el recuento que se ha hecho en las páginas anteriores de los impresos y otros esfuerzos llevados a cabo recientemente sobre el tema de la historia de la prensa en México ha tenido que ser forzosamente superficial, es posible hacer un diagnóstico de los adelantos y las carencias con cierta claridad.

Es posible detectar un avance en cuanto al interés que este objeto de estudio ha despertado entre los historiadores y otros académicos, dejando de ser un tema de aficionados y memoriosos locales.

También se ha visto que el centralismo que se veía en años pasados, ha logrado mitigarse, gracias al interés despertado en los académicos de

13 Véase Del Palacio (2004). Trabajo concebido desde esta teoría. 
provincia por recuperar y estudiar de manera sistemática y profesional su pasado periodístico, además de publicar local o regionalmente los resultados de sus investigaciones.

Sin embargo, aún se encuentran carencias importantes en este sentido. Se sabe muy poco de la historia periodística de Tabasco, Guerrero, Hidalgo, Tamaulipas, Nuevo León, Nayarit, Colima, Durango, Chihuahua y Tlaxcala.

Resulta fundamental estudiar los procesos periodísticos de las regiones de México, no sólo por el interés que pueda tener el rescate de la memoria histórica regional, sino porque si esto no sucede, se seguirá escribiendo una historia de la prensa en México que describa los procesos de la capital, no siempre (o casi nunca) semejantes de los de las regiones. Así mismo, sólo al recuperar la memoria periodística se podrán explicar los fenómenos contemporáneos, que también tienen profundas diferencias en cada una de las regiones de México.

Es importante saltar las barreras de la descripción de los fenómenos, el recuento historiográfico. Habría que considerar a éste como una primera etapa, fundamental e imprescindible, pero no suficiente, para explicar la historia de los periódicos en México.

La historia del periodismo es un objeto que tiene muchas dimensiones, de tal suerte que no es abordable desde una sola disciplina. Es absolutamente imprescindible apelar a la interdisciplinariedad, o bien a la hibridación de disciplinas (Wallerstein, 1996, 1998), para poder acercarse al fenómeno periodístico. No es únicamente abarcable desde la historia, o desde la comunicación, habrá que aplicar herramientas de la economía (no son suficientes todavía los análisis de las empresas periodísticas o de la publicidad, desde el punto de vista económico en los periódicos), del análisis político y social (existe un amplio campo de investigación en torno al papel protagónico de la prensa en la constitución de la esfera pública en México, sobre todo desde las regiones) y del análisis cultural (las relaciones casi endogámicas entre periodistas e intelectuales, gustos y preferencias de lectura, entre otras muchas posibilidades), para comenzar a entender a profundidad los procesos de evolución de la historia del periodismo mexicano.

La historia de la prensa, como la historia de los otros medios de comunicación, es una historia viva. Abordarla es asumirla como objeto 
vivo, cambiante, en movimiento. Si nos olvidamos de ella, veremos a los medios contemporáneos como algo estático, fotografías color sepia, borrosas y caducas aunque sean digitales.

Al escrutar la historia de los periódicos, el investigador de los medios de comunicación actuales podría descubrir cosas que seguramente en los estudios estáticos, de coyuntura, no aparecerán. De tal modo, se evitará considerar como novedad algo que es historia antigua.

Mientras, los historiadores deben seguir considerando a los periódicos como objeto de estudio complejo y digno de atención y no sólo como una fuente más para explicar el pasado.

\section{CUADRO 1}

\begin{tabular}{l|l|l|c|c}
\multicolumn{2}{c}{ Título } & Autor & México & 1998 \\
\hline $\begin{array}{l}\text { La prensa en México, } \\
\text { 1810-1915 }\end{array}$ & $\begin{array}{l}\text { Laura Navarrete } \\
\text { Maya y Blanca } \\
\text { Aguilar Plata } \\
\text { (coords.) }\end{array}$ & $\begin{array}{l}\text { Addison/ } \\
\text { Wesley/ } \\
\text { Longman }\end{array}$ & & \\
\hline $\begin{array}{l}\text { El Nacional y el hijo del } \\
\text { Ahuizote, dos visiones de } \\
\text { la Independencia de Cuba, } \\
\text { 1895-1898 }\end{array}$ & $\begin{array}{l}\text { Margarita } \\
\text { Espinoza Blas }\end{array}$ & UMSNH & Morelia & 1998 \\
\hline $\begin{array}{l}\text { El periodismo en México, }, \\
\text { 500 años de historia }\end{array}$ & $\begin{array}{l}\text { María del Carmen } \\
\text { Ruiz Castañeda y } \\
\text { Luis Reed }\end{array}$ & Edamex & México & 1998 \\
\hline $\begin{array}{l}\text { El estadio. La prensa en } \\
\text { México, 1870-1879 }\end{array}$ & $\begin{array}{l}\text { Marcelo Abramo } \\
\text { Lauff y Yolanda } \\
\text { Barberena } \\
\text { Villalobos }\end{array}$ & INAH & México & 1998 \\
\hline $\begin{array}{l}\text { Indice del Fondo } \\
\text { Hemerográfico } \\
\text { veracruzano }\end{array}$ & $\begin{array}{l}\text { Celia del Palacio } \\
\text { Montiel }\end{array}$ & $\begin{array}{l}\text { Universidad } \\
\text { Veracruzana }\end{array}$ & Jalapa & 1999 \\
\hline $\begin{array}{l}\text { Yerba, goma y polvo. } \\
\text { Drogas, ambientes y } \\
\text { policías en México, } \\
\text { 1900-1940 }\end{array}$ & $\begin{array}{l}\text { Ricardo Pérez } \\
\text { Montfort }\end{array}$ & $\begin{array}{l}\text { CONACULTA/ } \\
\text { Fototeca } \\
\text { nacional } \\
\text { del INAH en } \\
\text { Pachuca/ } \\
\text { Era }\end{array}$ & México & 1999 \\
\hline $\begin{array}{l}\text { Mariano de Jesús Torres. } \\
\text { Un polígrafo moreliano }\end{array}$ & $\begin{array}{l}\text { Adriana Pineda } \\
\text { Soto }\end{array}$ & UMSNH & Morelia & 1999 \\
\hline
\end{tabular}




\begin{tabular}{|c|c|c|c|c|}
\hline Título & Autor & Editorial & Lugar & Año \\
\hline $\begin{array}{l}\text { Índice de revistas literarias } \\
\text { del siglo XIX (ciudad de } \\
\text { México) }\end{array}$ & $\begin{array}{l}\text { María del Carmen } \\
\text { Ruiz Castañeda }\end{array}$ & IIFL/UNAM & México & 1999 \\
\hline $\begin{array}{l}\text { Imprenta, impresores y } \\
\text { periódicos en Guadalajara, } \\
1793-1811\end{array}$ & Carmen Castañeda & $\begin{array}{l}\text { Museo del } \\
\text { Periodismo/ } \\
\text { Agata/ } \\
\text { Ayuntamiento } \\
\text { Constitucional } \\
\text { de Guadalajara/ } \\
\text { CIESAS }\end{array}$ & Guadalajara & 1999 \\
\hline $\begin{array}{l}\text { La prensa en Sinaloa } \\
\text { durante el cañedismo, } \\
1877-1911\end{array}$ & $\begin{array}{l}\text { Jorge Briones } \\
\text { Franco }\end{array}$ & $\begin{array}{l}\text { UAS-Dirección } \\
\text { de Investigación } \\
\text { y Fomento } \\
\text { a la Cultura } \\
\text { Regional } \\
\end{array}$ & Culiacán & 1999 \\
\hline $\begin{array}{l}\text { La historia de la imprenta } \\
\text { en Oaxaca }\end{array}$ & $\begin{array}{l}\text { Isabel Grañén } \\
\text { Porrúa, Carlos } \\
\text { Sánchez Silva, } \\
\text { Nimcy Arellanes } \\
\text { Cancino, } \\
\text { Francisco José } \\
\text { Ruiz Cervantes y } \\
\text { Anselmo Arellanes } \\
\text { Meixueiro }\end{array}$ & $\begin{array}{l}\text { Biblioteca } \\
\text { Burgoa }\end{array}$ & Oaxaca & 1999 \\
\hline $\begin{array}{l}\text { La caricatura política en } \\
\text { México en el siglo XIX }\end{array}$ & Esther Acevedo & CONACULTA & México & 2000 \\
\hline $\begin{array}{l}\text { Publicaciones periódicas } \\
\text { mexicanas del siglo XIX, } \\
1822-1855\end{array}$ & $\begin{array}{l}\text { Miguel Ángel } \\
\text { Castro (comp.) }\end{array}$ & UNAM & México & 2000 \\
\hline $\begin{array}{l}\text { Historia de la prensa en } \\
\text { Iberoamérica }\end{array}$ & $\begin{array}{l}\text { Celia del Palacio } \\
\text { Montiel (comp.) }\end{array}$ & Altexto & Guadalajara & 2000 \\
\hline $\begin{array}{l}\text { La disputa por las } \\
\text { conciencias, los inicios de } \\
\text { la prensa en Guadalajara, } \\
1809-1835\end{array}$ & $\begin{array}{l}\text { Celia del Palacio } \\
\text { Montiel }\end{array}$ & UdeG & Guadalajara & 2001 \\
\hline $\begin{array}{l}\text { Empresa y cultura en tinta } \\
\text { y papel, } 1800-1860\end{array}$ & $\begin{array}{l}\text { Laura Suárez de la } \\
\text { Torre (coord.) }\end{array}$ & $\begin{array}{l}\text { UNAM/Instituto } \\
\text { Mora }\end{array}$ & México & 2001 \\
\hline
\end{tabular}




\begin{tabular}{|c|c|c|c|c|}
\hline Título & Autor & Editorial & Lugar & Año \\
\hline $\begin{array}{l}\text { Tipos y caracteres, la } \\
\text { prensa mexicana, } 1822- \\
1855\end{array}$ & $\begin{array}{l}\text { Miguel Ángel } \\
\text { Castro (comp.) }\end{array}$ & UNAM & México & 2001 \\
\hline $\begin{array}{l}\text { Bibliohemerografía } \\
\text { del sureste mexicano y } \\
\text { Centroamérica. Época } \\
\text { colonial }\end{array}$ & $\begin{array}{l}\text { Octavio Gordillo } \\
\text { y Ortiz }\end{array}$ & UNAM & México & 2001 \\
\hline El Despertador Americano & Carlos Fregoso & UdeG & Guadalajara & 2001 \\
\hline $\begin{array}{l}\text { México } 1900 . \text { Percepciones } \\
\text { y valores en la gran prensa } \\
\text { diaria }\end{array}$ & $\begin{array}{l}\text { Nora Pérez Rayón } \\
\text { Elizundia }\end{array}$ & $\begin{array}{l}\text { UAM } \\
\text { Azcapotzalco/ } \\
\text { Miguel Ángel } \\
\text { Porrúa }\end{array}$ & México & 2001 \\
\hline $\begin{array}{l}\text { El periódico oficial de } \\
\text { Nuevo León. Un periódico } \\
\text { con } 175 \text { años de vida }\end{array}$ & $\begin{array}{l}\text { Erasmo E. Torres } \\
\text { López }\end{array}$ & AGNL & Monterrey & 2001 \\
\hline $\begin{array}{l}\text { Estudio e índice } \\
\text { onomástico del Diario de } \\
\text { México. Primera época, } \\
1805-1812\end{array}$ & $\begin{array}{l}\text { Esther Martínez } \\
\text { Luna }\end{array}$ & UNAM & México & 2002 \\
\hline $\begin{array}{l}\text { La obra periodística de } \\
\text { Amado Nervo en El Correo } \\
\text { de la Tarde, } 1892-1894\end{array}$ & $\begin{array}{l}\text { Mayra Elena } \\
\text { Fonseca Ávalos }\end{array}$ & $\begin{array}{l}\text { Gobierno } \\
\text { del estado } \\
\text { de Nayarit/ } \\
\text { Universidad } \\
\text { Autónoma } \\
\text { de Nayarit/ } \\
\text { Ayuntamiento } \\
\text { de Tepic }\end{array}$ & Tepic & 2002 \\
\hline Del autor al lector & $\begin{array}{l}\text { Carmen Castañeda } \\
\text { (coord.) }\end{array}$ & $\begin{array}{l}\text { Miguel Ángel } \\
\text { Porrúa/CIESAS/ } \\
\text { CONACYT }\end{array}$ & México & 2002 \\
\hline $\begin{array}{l}\text { Imágenes de México. Las } \\
\text { Historias de El Buen Tono } \\
\text { de Juan B. Urrutia, 1909- } \\
1912\end{array}$ & $\begin{array}{l}\text { Thelma Camacho } \\
\text { Morfín }\end{array}$ & Instituto Mora & México & 2002 \\
\hline $\begin{array}{l}\text { El siglo de Cumplido. La } \\
\text { emergencia del periodismo } \\
\text { mexicano de opinión, } \\
1832-1857\end{array}$ & $\begin{array}{l}\text { Irma Lombardo } \\
\text { García }\end{array}$ & UNAM & México & 2002 \\
\hline
\end{tabular}




\begin{tabular}{|c|c|c|c|c|}
\hline Título & Autor & Editorial & Lugar & Año \\
\hline $\begin{array}{l}\text { Treinta años, historia y } \\
\text { testimonios. Hemeroteca } \\
\text { Pública de Oaxaca. Néstor } \\
\text { Sánchez, 1992-2002 }\end{array}$ & $\begin{array}{l}\text { Prometeo Sánchez } \\
\text { Islas }\end{array}$ & $\begin{array}{l}\text { Carteles } \\
\text { Editores }\end{array}$ & Oaxaca & 2002 \\
\hline $\begin{array}{l}\text { La Palabra. Edición } \\
\text { facsimilar, } 1917 .\end{array}$ & $\begin{array}{l}\text { Alfonso Nuño } \\
\text { Rodríguez }\end{array}$ & $\begin{array}{l}\text { Alfonso Nuño } \\
\text { Rodríguez }\end{array}$ & Guadalajara & 2002 \\
\hline $\begin{array}{l}\text { El periódico El Imparcial. } \\
\text { Primer diario moderno de } \\
\text { México, 1896-1914 }\end{array}$ & $\begin{array}{l}\text { Clara Guadalupe } \\
\text { García }\end{array}$ & CEHIPO & México & 2003 \\
\hline $\begin{array}{l}\text { Tiempo de Saber. Prensa y } \\
\text { poder en México }\end{array}$ & $\begin{array}{l}\text { Julio Scherer } \\
\text { García y Carlos } \\
\text { Monsivais }\end{array}$ & $\begin{array}{l}\text { Nuevo Siglo/ } \\
\text { Aguilar }\end{array}$ & México & 2003 \\
\hline $\begin{array}{l}\text { Vida cotidiana, ciudad de } \\
\text { México, } 1850-1910\end{array}$ & $\begin{array}{l}\text { Cristina Barros y } \\
\text { Marco Buenrrostro }\end{array}$ & $\begin{array}{l}\text { CONACULTA/ } \\
\text { FCE }\end{array}$ & México & 2003 \\
\hline $\begin{array}{l}\text { Los orígenes del } \\
\text { periodismo en nuestra } \\
\text { América }\end{array}$ & $\begin{array}{l}\text { José Antonio } \\
\text { Benítez }\end{array}$ & Lumen México & México & 2003 \\
\hline $\begin{array}{l}\text { La prensa decimonónica en } \\
\text { México }\end{array}$ & $\begin{array}{l}\text { Adriana Pineda } \\
\text { Soto y Celia del } \\
\text { Palacio Montiel } \\
\text { (coords.) } \\
\end{array}$ & $\begin{array}{l}\text { UdeG/ } \\
\text { CONACYT/ } \\
\text { UMSNH }\end{array}$ & Morelia & 2003 \\
\hline $\begin{array}{l}\text { Publicaciones periódicas } \\
\text { mexicanas del siglo XIX, } \\
\text { 1856-1876. Parte I }\end{array}$ & $\begin{array}{l}\text { Miguel Ángel } \\
\text { Castro (comp.) }\end{array}$ & UNAM & México & 2003 \\
\hline $\begin{array}{l}\text { Imágenes del Deseo. Arte } \\
\text { y publicidad en la prensa } \\
\text { ilustrada mexicana, 1894- } \\
1939\end{array}$ & $\begin{array}{l}\text { Julieta Ortiz } \\
\text { Gaytán }\end{array}$ & UNAM & México & 2003 \\
\hline $\begin{array}{l}\text { Los oaxaqueños pintados } \\
\text { por sí mismos. La } \\
\text { caricatura en el periódico } \\
\text { El Ciclón, } 1927-1929 \\
\end{array}$ & $\begin{array}{l}\text { Francisco José } \\
\text { Ruiz Cervantes y } \\
\text { Carlos Sánchez } \\
\text { Silva }\end{array}$ & $\begin{array}{l}\text { IIHUABJO/ } \\
\text { Carteles } \\
\text { Editores }\end{array}$ & Oaxaca & 2004 \\
\hline $\begin{array}{l}\text { Bicentenario de la Prensa } \\
\text { Provincial en México. } \\
\text { Estudios sobre periodismo } \\
\text { veracruzano }\end{array}$ & $\begin{array}{l}\text { Francisco } \\
\text { Morosini, Ramón } \\
\text { Moreno y Roberto } \\
\text { Sánchez (coords.) }\end{array}$ & $\begin{array}{l}\text { Gobierno } \\
\text { del estado } \\
\text { de Veracruz/ } \\
\text { Instituto } \\
\text { Veracruzano de } \\
\text { la Cultura. }\end{array}$ & $\begin{array}{c}\text { Jalapa, } \\
\text { Veracruz }\end{array}$ & 2004 \\
\hline $\begin{array}{l}\text { Ricardo Arenales. El poeta } \\
\text { colombiano que fundó El } \\
\text { Porvenir }\end{array}$ & $\begin{array}{l}\text { Erasmo Torres } \\
\text { López }\end{array}$ & \begin{tabular}{l|} 
Colegio de \\
Cronistas e \\
Historiadores \\
de Nuevo León.
\end{tabular} & Monterrey & 2004 \\
\hline
\end{tabular}




\begin{tabular}{l|l|l|l|c}
\multicolumn{2}{c}{ Título } & Autor & Lugar & Año \\
\hline $\begin{array}{l}\text { Catálogo Hemerográfico } \\
\text { de Michoacán }\end{array}$ & $\begin{array}{l}\text { Adriana Pineda } \\
\text { Soto }\end{array}$ & $\begin{array}{l}\text { UdeG/ } \\
\text { Universidad } \\
\text { Michoacana } \\
\text { de San Nicolás } \\
\text { de Hidalgo/ } \\
\text { CONACYT }\end{array}$ & Guadajara & 2004 \\
\hline $\begin{array}{l}\text { Catálogo de la } \\
\text { Hemerografía } \\
\text { de Zacatecas }\end{array}$ & $\begin{array}{l}\text { Marco Antonio } \\
\text { Flores Zavala }\end{array}$ & $\begin{array}{l}\text { UdeG/ } \\
\text { CONACYT }\end{array}$ & Guadalajara & 2004 \\
$\begin{array}{l}\text { Catálogo Hemerográfico } \\
\text { de Chiapas }\end{array}$ & Sarelly Martínez & $\begin{array}{l}\text { UdeG/ } \\
\text { CONACYT }\end{array}$ & Guadalajara & 2004 \\
$\begin{array}{l}\text { La prensa maniatada. El } \\
\text { periodismo en Chiapas de } \\
\text { 1827 a 1958 }\end{array}$ & Sarelly Martínez & $\begin{array}{l}\text { Gobierno } \\
\text { del estado de } \\
\text { Chiapas }\end{array}$ & Gutiérrez & 2004 \\
\hline $\begin{array}{l}\text { Catálogo de la } \\
\text { hemerografía de Oaxaca }\end{array}$ & $\begin{array}{l}\text { Carlos Sánchez } \\
\text { Silva y Francisco } \\
\text { Ruiz Cervantes }\end{array}$ & $\begin{array}{l}\text { UdeG/ } \\
\text { CONACYT }\end{array}$ & Guadalajara & 2004 \\
\hline $\begin{array}{l}\text { Registro de la prensa } \\
\text { política michoacana, } \\
\text { siglo XIX }\end{array}$ & $\begin{array}{l}\text { Adriana Pineda } \\
\text { Soto }\end{array}$ & $\begin{array}{l}\text { UdeG/ } \\
\text { Universidad } \\
\text { Michoacana de } \\
\text { San Nicolás de } \\
\text { Hidalgo/ } \\
\text { CONACYT }\end{array}$ & Guadalaja- \\
ra-Morelia & 2004 \\
& & & & \\
\hline
\end{tabular}

\section{CUADRO 2}

TIPOS DE PUBLICACIONES

\begin{tabular}{lcc}
\multicolumn{1}{c}{ Tipo de publicación } & Número & Porcentaje \\
\hline Publicaciones colectivas & 7 & 17.5 \\
Prensa como fuente & 3 & 7.5 \\
Selección de textos, fotografías, caricaturas & 5 & 12.5 \\
Índices, catálogos y otras guías & 11 & 25.0 \\
Historias generales & 2 & 5.0 \\
Historias generales acotadas & 2 & 5.0 \\
a un tema o periodo & & \\
Historias regionales & 6 & 12.5 \\
Estudios monográficos & 6 & 15.0 \\
& 42 & 100 \\
\hline
\end{tabular}




\section{CUADRO 3}

LUGAR DE PUBLICACIÓN

\begin{tabular}{lcc}
\multicolumn{1}{c}{ Lugar de publicación } & Número & Porcentaje \\
\hline Distrito Federal & 22 & 55 \\
Los estados & 20 & 45 \\
\hline
\end{tabular}

CUADRO 4

ORIGEN DISCIPLINAR DE LOS AUTORES

\begin{tabular}{lcc}
\multicolumn{1}{c}{ Origen disciplinar } & Número & Porcentaje \\
\hline Historiadores & 24 & 63.15 \\
Literatos & 6 & 15.78 \\
Periodistas y aficionados & 5 & 13.15 \\
Comunicólogos & 3 & 7.89 \\
& & 99.97 \\
\hline
\end{tabular}

\begin{tabular}{|c|c|c|c|c|}
\hline \multicolumn{5}{|c|}{$\begin{array}{c}\text { CUADRO } 5 \\
\text { TESIS DE POSGRADO }\end{array}$} \\
\hline Título & Autor & Universidad & Grado y disciplina & Año \\
\hline $\begin{array}{l}\text { Las primeras reporteras } \\
\text { mexicanas: Magdalena } \\
\text { Mondragón, Elvira Vargas } \\
\text { y Esperanza Velásquez }\end{array}$ & $\begin{array}{l}\text { Elvira Laura } \\
\text { Hernández } \\
\text { Carballido }\end{array}$ & $\begin{array}{l}\text { UNAM- } \\
\text { FCPYS }\end{array}$ & $\begin{array}{l}\text { Maestría en } \\
\text { comunicación }\end{array}$ & 1997 \\
\hline $\begin{array}{l}\text { Adelina Zendejas, } \\
\text { precursora de la escritura } \\
\text { y el periodismo femeninos }\end{array}$ & $\begin{array}{l}\text { Josefina } \\
\text { Hernández } \\
\text { Téllez }\end{array}$ & $\begin{array}{l}\text { UNAM- } \\
\text { FCPYS }\end{array}$ & $\begin{array}{l}\text { Maestría en } \\
\text { comunicación }\end{array}$ & 2001 \\
\hline $\begin{array}{l}\text { Surgimiento de una } \\
\text { empresa periodística. Siglo } \\
\text { XIX. Periodismo } \\
\text { emergente }\end{array}$ & Irma Lombardo & $\begin{array}{l}\text { UNAM- } \\
\text { FCPYS }\end{array}$ & $\begin{array}{l}\text { Maestría en } \\
\text { Comunicación }\end{array}$ & 1998 \\
\hline $\begin{array}{l}\text { Excélsior, sus primeros } \\
\text { años }\end{array}$ & \begin{tabular}{l|} 
María \\
Guadalupe \\
Laura Navarrete \\
Maya
\end{tabular} & $\begin{array}{l}\text { UNAM- } \\
\text { FCPYS }\end{array}$ & $\begin{array}{l}\text { Maestría en } \\
\text { comunicación }\end{array}$ & 2001 \\
\hline
\end{tabular}


Título

Autor Universidad Grado y disciplina Año

\begin{tabular}{|c|c|c|c|c|}
\hline $\begin{array}{l}\text { La representación } \\
\text { femenina en revistas de } \\
\text { difusión popular }\end{array}$ & $\begin{array}{l}\text { Alina Plascencia } \\
\text { Vela }\end{array}$ & $\begin{array}{l}\text { ITESM- } \\
\text { Monterrey }\end{array}$ & $\begin{array}{l}\text { Maestría en } \\
\text { ciencias sociales } \\
\text { con especialidad } \\
\text { en comunicación }\end{array}$ & 1999 \\
\hline $\begin{array}{l}\text { Ser mujer y ser periodista. } \\
\text { Condiciones laborales } \\
\text { de los periodistas en el } \\
\text { diarios de la ciudad de } \\
\text { México }\end{array}$ & $\begin{array}{l}\text { Patricia Ríos } \\
\text { Reyes }\end{array}$ & $\begin{array}{l}\text { UNAM- } \\
\text { FCPYS }\end{array}$ & $\begin{array}{l}\text { Maestría en } \\
\text { comunicación }\end{array}$ & 1999 \\
\hline $\begin{array}{l}\text { La entrevista periodística } \\
\text { como relato. Una } \\
\text { secuencia de evocaciones }\end{array}$ & $\begin{array}{l}\text { Francisca } \\
\text { Robles }\end{array}$ & $\begin{array}{l}\text { UNAM- } \\
\text { FCPYS }\end{array}$ & $\begin{array}{l}\text { Maestría en } \\
\text { comunicación }\end{array}$ & 1998 \\
\hline $\begin{array}{l}\text { Una mujer columnista. } \\
\text { Marcela Guijosa y su } \\
\text { «Querido Diario» en la } \\
\text { revista Fem }\end{array}$ & $\begin{array}{l}\text { María de } \\
\text { Lourdes Ruiz } \\
\text { Pavón }\end{array}$ & $\begin{array}{l}\text { UNAM- } \\
\text { FCPYS }\end{array}$ & $\begin{array}{l}\text { Maestría en } \\
\text { comunicación }\end{array}$ & 2001 \\
\hline $\begin{array}{l}\text { Ejes de la apertura y } \\
\text { modernización periodística } \\
\text { durante el sexenio de } \\
\text { Miguel de la Madrid }\end{array}$ & $\begin{array}{l}\text { Hugo Luis } \\
\text { Sánchez } \\
\text { Garduño }\end{array}$ & $\begin{array}{l}\text { UNAM- } \\
\text { FCPYS }\end{array}$ & $\begin{array}{l}\text { Maestría en } \\
\text { comunicación }\end{array}$ & 1996 \\
\hline $\begin{array}{l}\text { El discurso político en } \\
\text { la presentación social de } \\
\text { la caricatura política: } \\
\text { la figura presidencial de } \\
\text { Carlos Salinas }\end{array}$ & $\begin{array}{l}\text { María del } \\
\text { Socorro Tapia }\end{array}$ & $\begin{array}{l}\text { UNAM- } \\
\text { FCPYS }\end{array}$ & $\begin{array}{l}\text { Maestría en } \\
\text { comunicación }\end{array}$ & 1999 \\
\hline $\begin{array}{l}\text { La función de mitificación } \\
\text { en El Correo de la Tarde }\end{array}$ & $\begin{array}{l}\text { Mayra Elena } \\
\text { Fonseca }\end{array}$ & UdeG & $\begin{array}{l}\text { Maestría en } \\
\text { comunicación }\end{array}$ & 2002 \\
\hline $\begin{array}{l}\text { Representación y praxis } \\
\text { de la revista literaria en } \\
\text { México }\end{array}$ & $\begin{array}{l}\text { Juan Pedro } \\
\text { Delgado }\end{array}$ & UdeG & $\begin{array}{l}\text { Maestría en } \\
\text { comunicación }\end{array}$ & 2002 \\
\hline $\begin{array}{l}\text { La prensa política en } \\
\text { Michoacán }\end{array}$ & $\begin{array}{l}\text { Adriana Pineda } \\
\text { Soto }\end{array}$ & $\begin{array}{l}\text { UNAM- } \\
\text { FFYL }\end{array}$ & $\begin{array}{l}\text { Doctorado en } \\
\text { historia }\end{array}$ & 2003 \\
\hline $\begin{array}{l}\text { La caricatura como } \\
\text { expresión del descontento } \\
\text { político y crítica social } \\
\text { en la prensa durante el } \\
\text { Porfiriato }\end{array}$ & Fausta Gantús & $\begin{array}{l}\text { El Colegio } \\
\text { de México }\end{array}$ & $\begin{array}{l}\text { Doctorado en } \\
\text { historia }\end{array}$ & 2002 \\
\hline
\end{tabular}




\section{CUADRO 6}

\section{ARTÍCULOS}

\begin{tabular}{|c|c|c|c|c|}
\hline Título & Autor & Revista & Lugar & Año \\
\hline $\begin{array}{l}\text { «El cosmopolita de Kansas } \\
\text { City, un periódico para } \\
\text { mexicanos» }\end{array}$ & $\begin{array}{l}\text { Michael Smith y } \\
\text { Jorge Durand }\end{array}$ & $\begin{array}{l}\text { Frontera Norte, } \\
\text { 26. Julio- } \\
\text { diciembre }\end{array}$ & Tijuana & 2001 \\
\hline $\begin{array}{l}\text { «Historiografía de la } \\
\text { prensa regional en } \\
\text { México» }\end{array}$ & $\begin{array}{l}\text { Celia del } \\
\text { Palacio Montiel }\end{array}$ & $\begin{array}{l}\text { Comunicación } \\
\text { y sociedad, } 33 . \\
\text { Mayo-agosto }\end{array}$ & Guadalajara & 1998 \\
\hline $\begin{array}{l}\text { «Impugnar los errores } \\
\text { de los últimos siglos, } \\
\text { la función educativa } \\
\text { de la prensa mexicana } \\
\text { decimonónica» }\end{array}$ & $\begin{array}{l}\text { Celia del } \\
\text { Palacio Montiel }\end{array}$ & $\begin{array}{l}\text { Comunicación } \\
\text { y Sociedad, } 34 . \\
\text { Septiembre- } \\
\text { diciembre }\end{array}$ & Guadalajara & 1998 \\
\hline $\begin{array}{l}\text { «a libertad de imprenta } \\
\text { durante el segundo } \\
\text { imperio» }\end{array}$ & $\begin{array}{l}\text { Angélica } \\
\text { Hernández }\end{array}$ & $\begin{array}{l}\text { Historias, } 42 . \\
\text { Enero-abril }\end{array}$ & México & 1999 \\
\hline $\begin{array}{l}\text { «La prensa procultural de } \\
\text { Michoacán hacia finales } \\
\text { del siglo XIX» }\end{array}$ & $\begin{array}{l}\text { Adriana } \\
\text { Pineda Soto }\end{array}$ & $\begin{array}{l}\text { Revista } \\
\text { Universidad de } \\
\text { Guadalajara, } 28 . \\
\text { Verano }\end{array}$ & Guadalajara & 2003 \\
\hline «Prensa e historia cultural» & \begin{tabular}{|l|} 
Celia del \\
Palacio Montiel
\end{tabular} & $\begin{array}{l}\text { Revista } \\
\text { Universidad de } \\
\text { Guadalajara, } 28 . \\
\text { Verano }\end{array}$ & Guadalajara & 2003 \\
\hline $\begin{array}{l}\text { «ropaganda impresa y } \\
\text { construcción de un espacio } \\
\text { ideológico y cultural en } \\
\text { Guadalajara, siglo XIX» }\end{array}$ & $\begin{array}{l}\text { Pilar Gutiérrez } \\
\text { Lorenzo }\end{array}$ & $\begin{array}{l}\text { Revista } \\
\text { Universidad de } \\
\text { Guadalajara, } 28 . \\
\text { Verano }\end{array}$ & Guadalajara & 2003 \\
\hline $\begin{array}{l}\text { «a prensa mexicana } \\
\text { de la segunda mitad } \\
\text { del siglo XX» }\end{array}$ & $\begin{array}{l}\text { Armando } \\
\text { Zacarías Castillo }\end{array}$ & $\begin{array}{l}\text { Revista } \\
\text { Universidad de } \\
\text { Guadalajara, } 28 . \\
\text { Verano }\end{array}$ & Guadalajara & 2003 \\
\hline $\begin{array}{l}\text { «Representación y praxis } \\
\text { de la revista literaria en } \\
\text { México» }\end{array}$ & $\begin{array}{l}\text { Juan Pedro } \\
\text { Delgado Pérez }\end{array}$ & $\begin{array}{l}\text { Revista } \\
\text { Universidad de } \\
\text { Guadalajara, } 28 . \\
\text { Verano }\end{array}$ & Guadalajara & 2003 \\
\hline
\end{tabular}




\section{Bibliografía}

Del PALACIO Montiel, Celia (1998) «Historiografía de la prensa regional en México». En Revista Comunicación y sociedad, 33. Mayoagosto. Guadalajara: UdeG-DECS.

FUENTES, Raul (1998) La emergencia de un campo académico: continuidad utópica y estructuración científica de la investigación de la comunicación en México. Guadalajara: UdeG-CUCSH/ITESO.

- (2003) La investigación académica sobre comunicación en México. Sistematización documental, 1995-2000. Guadalajara: ITESO.

MARTín Serrano, Manuel (1986) La producción social de comunicación. Madrid: Alianza.

SÁNCHEZ Ruiz, Enrique (1992) Medios de difusión y sociedad. Notas críticas y metodológicas. Guadalajara: UdeG.

WALLERSTEIN, Immanuel (1996) Abrir las ciencias sociales. México: Siglo XXI.

- (1998) Impensar las ciencias sociales. México: Siglo XXI/UNAM.

Fecha de recepción: 14/06/2005. Aceptación: 23/10/2005. 